University of Nebraska - Lincoln

DigitalCommons@University of Nebraska - Lincoln

Publications from USDA-ARS / UNL Faculty

U.S. Department of Agriculture: Agricultural

Research Service, Lincoln, Nebraska

November 1992

\title{
Simulating winter wheat spike development and growth
}

\author{
Gregory S. McMaster \\ USDA-ARS, greg.mcmaster@ars.usda.gov \\ Jack A. Morgan \\ USDA-ARS \\ Wallace Wilhelm \\ University of Nebraska-Lincoln, wwilhelm1@unl.edu
}

Follow this and additional works at: https://digitalcommons.unl.edu/usdaarsfacpub

Part of the Agricultural Science Commons

McMaster, Gregory S.; Morgan, Jack A.; and Wilhelm, Wallace, "Simulating winter wheat spike development and growth" (1992). Publications from USDA-ARS / UNL Faculty. 91.

https://digitalcommons.unl.edu/usdaarsfacpub/91

This Article is brought to you for free and open access by the U.S. Department of Agriculture: Agricultural Research Service, Lincoln, Nebraska at DigitalCommons@University of Nebraska - Lincoln. It has been accepted for inclusion in Publications from USDA-ARS / UNL Faculty by an authorized administrator of DigitalCommons@University of Nebraska - Lincoln. 


\title{
Simulating winter wheat spike development and growth
}

\author{
Gregory S. McMaster ${ }^{\mathrm{a}}$, Jack A. Morgan ${ }^{\mathrm{b}}$ and W.W. Wilhelm ${ }^{\mathrm{c}}$ \\ ${ }^{a}$ USDA-ARS, Great Plains Systems Research Unit, 301 S. Howes, P.O. Box E, Fort Collins, CO 80522, \\ USA \\ ${ }^{\mathrm{b}}$ USDA-ARS, Rangeland Resources Research Unit, 1701 Center Avenue, Fort Collins, CO 80526, USA \\ ${ }^{\circ}$ USDA-ARS, Department of Agronomy, University of Nebraska, Lincoln, NE 68583, USA
}

(Revision received 3 February 1992; accepted 30 March 1992)

\section{ABSTRACT}

McMaster, G.S., Morgan, J.A. and Wilhelm, W.W., 1992. Simulating winter wheat spike development and growth. Agric. For. Meteorol,, 60: 193-220.

Mechanistic crop simulation models can aid in integrating and directing research, and in improving farm management strategies. Information derived from recent research on spike development and growth of winter wheat (Triticum aestivum L.) was incorporated into a submodel, SPIKEGRO, and added to an existing model called SHOOTGRO. This manuscript discusses the SPIKEGRO submodel.

SPIKEGRO emphasizes the reproductive functioning of the shoot apex. The complete developmental sequence of the shoot apex is outlined and quantified. All developmental events and growth stages are predicted, most using the phyllochron approach. Spikelet and floret primordium initiation, growth, and abortion; ovule fertilization and growth; and rachis and chaff growth are simulated on morphologicallyidentified culms. The phyllochron interval, rather than growing degree-days, is used throughout the model to increase flexibility in predicting yearly and within-stand variation in development. Up to six cohorts of plants are simulated simultaneously from time of emergence, using a daily time step. Initial inputs consist of general agronomic information such as planting date, density, and depth, site latitude, cultivar heightclass, soil water and $\mathrm{N}$ concentration, and soil characteristics (e.g. bulk density, organic carbon, parameters for a water-release curve). Cultivar differences, if known, can be incorporated by changing the input parameter file.

Validation results and sensitivity analysis suggested six modifications that should improve model realism and predictions. Most of the modifications are easy corrections of simplified algorithms.

SPIKEGRO integrates aboveground development and growth of individual plant components into one simulation. The model is useful in estimating development and growth throughout the growing season, and in predicting all stages of shoot apex development critical in scheduling cultural practices.

Correspondence to: G.S. McMaster, USDA-ARS, Great Plains Systems Research Unit, P.O. Box E, Fort Collins, CO 80522, USA. 


\section{INTRODUCTION}

Crop management strategies for winter wheat (Triticum aestivum L.) are becoming more oriented towards stage of plant development. Efficacy of herbicides and pesticides is largely a function of crop growth stage, and optimal irrigation and fertilizer applications are coordinated with specific developmental events. Mechanistic simulation models can be useful in quantifying plant processes and their interactions, and have been constructed to estimate winter wheat development and growth (e.g. Weir et al., 1984; Ritchie, 1985; Baker, et al., 1985). With few exceptions, much of the research in the last decade on winter wheat development, phenology, and growth (e.g. Masle-Meynard and Sebillotte, 1981; Klepper et al., 1982, 1984; Kirby, 1985; Delecolle et al., 1989; Kirby et al., 1989) has not been incorporated into the 74 wheat yield simulation models known to the authors (McMaster, 1991). Further, as Kirby (1985) noted, few existing wheat models simulate at the level of shoot apex function. Many developmental events are omitted from these models, particularly those developmental events that are not readily observed in the field.

A simulation model called SPIKEGRO was developed to simulate the development and growth of a population of winter wheat shoot apices in a stand. This model simulates the differentiation of tissue at the shoot apex into plant organs of leaf blades and sheaths, axillary buds, internodes, spikelets, florets, kernels, rachises, and chaff. Subsequent growth and senescence of these plant tissues are followed on morphologically identified culms within a plant for up to six cohorts, or age classes, of plants. Simulation begins with planting and ends with physiological maturity.

Some of the distinguishing features of SPIKEGRO are: (1) processes are simulated for different cohorts of plants determined by the time of emergence, which introduces a population element into the model; (2) within each cohort, all processes are simulated for morphologically identified culms using the nomenclature of Klepper et al. (1983); (3) the entire developmental sequence of the shoot apex is quantified, with the phyllochron concept serving as the fundamental measure of thermal time; (4) developmental events are simulated beginning with primordia initiation, and subsequent differentiation, growth, and abortion are followed.

The primary purpose of SPIKEGRO was to incorporate research on shoot apex functioning of the last decade into integrated submodels that could provide a suitable framework for easily adding new research by modifying the existing submodels. This paper will describe the conceptualization of the SPIKEGRO submodels, followed by model evaluation consisting of submodel validation and sensitivity analysis. 
MODEL OVERVIEW

SPIKEGRO is written in standard FORTRAN 77 and runs on machines using the UNIX, VMS, and MS-DOS operating systems. On a Sun Microsystems IPS SparcStation, SPIKEGRO uses about $20 \mathrm{~s}$ of CPU for simulating one growing season.

SPIKEGRO is an expansion of another model called SHOOTGRO. SHOOTGRO simulates the vegetative development and growth of the winter wheat shoot apex from planting through growth of the penultimate internode on the main stem (to early booting). Several cohorts, or age classes, of plants (maximum of six) are simulated based on time of emergence. SHOOTGRO 1.0 is the initial version for simulating development and growth under nonstressed conditions (McMaster et al., 1991). Initial inputs to the model are cultivar type (dwarf, semi-dwarf, mid-tall, and tall), seeding rate, seeding depth and date, and latitude. Temperature drives SHOOTGRO 1.0 and processes are simulated with a daily time step.

SHOOTGRO 2.0 (Wilhelm et al., 1990) expanded SHOOTGRO 1.0 by modifying some of the concepts in SHOOTGRO 1.0 and by adding water and $\mathrm{N}$ stress affects. Additional inputs for SHOOTGRO 2.0 are daily radiation (PAR), initial soil water and available $\mathrm{N}$ levels, and soil characteristics (bulk density, $\mathrm{pH}$, albedo, organic carbon content, hydraulic conductivity, and parameters for a water-release curve; McMaster, 1991). The soil water and N balance submodels are from CERES-Wheat (Godwin and Vlek, 1985). Water and $\mathrm{N}$ resource availability indices are multiplied to generate a total resource availability index. System processes are then altered by using specific relationships with the total resource availability index.

SPIKEGRO expands SHOOTGRO 2.0 by simulating the reproductive development and growth of the winter wheat shoot apex. Spikelet and floret development, growth, and abortion; floret fertilization and subsequent kernel growth; and peduncle, rachis, and chaff growth are simulated for each culm on a plant in each age class. The same inputs for initial conditions are needed for SPIKEGRO as for SHOOTGRO 2.0.

The morphological nomenclature used in SHOOTGRO and SPIKEGRO (Klepper et al., 1983) identifies each phytomer unit consisting of a leaf and node plus associated internode, and follows their appearance, development, growth, and senescence. Leaves are numbered acropetally on a culm, with the first true leaf designated L1. Culms are either the main stem (MS) or tillers. Tiller appearance is based on the MS Haun growth stage scale (Haun, 1973; McMaster et al., 1991).

The phyllochron is used to predict organ morphogenesis in SHOOTGRO and SPIKEGRO. The phyllochron is defined as the mean time, in accumulated growing degree-days (GDD), for successive leaves on a shoot to appear. A $0^{\circ} \mathrm{C}$ base temperature is used in accumulating GDD (Gallagher, 1979; 
Gallagher et al., 1979; McMaster and Smika, 1988). SHOOTGRO and SPIKEGRO simulate the observed tendency for wheat to have a constant phyllochron during the growing season (Friend, 1965b; Malse-Meynard and Sebillote, 1981; Kirby et al., 1982, 1989; Rawson et al., 1983; Malvoisin, 1984; Baker et al., 1986; Belford et al., 1987; Delecolle et al., 1989). The phyllochron is related to daily change of day length at emergence (Baker et al., 1980; Kirby et al., 1982, 1989; Delecolle et al., 1985; Kirby and Perry, 1987) by the algorithm (corrected) reported by Baker et al. (1980)

phyllochron $=\frac{1}{(0.026 * \Delta d)+0.0104}$

where $\Delta d$ is the change in day length (in hours) for successive days at emergence. Because cohorts emerge on different days, the phyllochron, and thus developmental rates, will vary slightly among plants in different cohorts.

\section{SHOOT APEX DEVELOPMENTAL SEQUENCE} AND PHENOLOGY
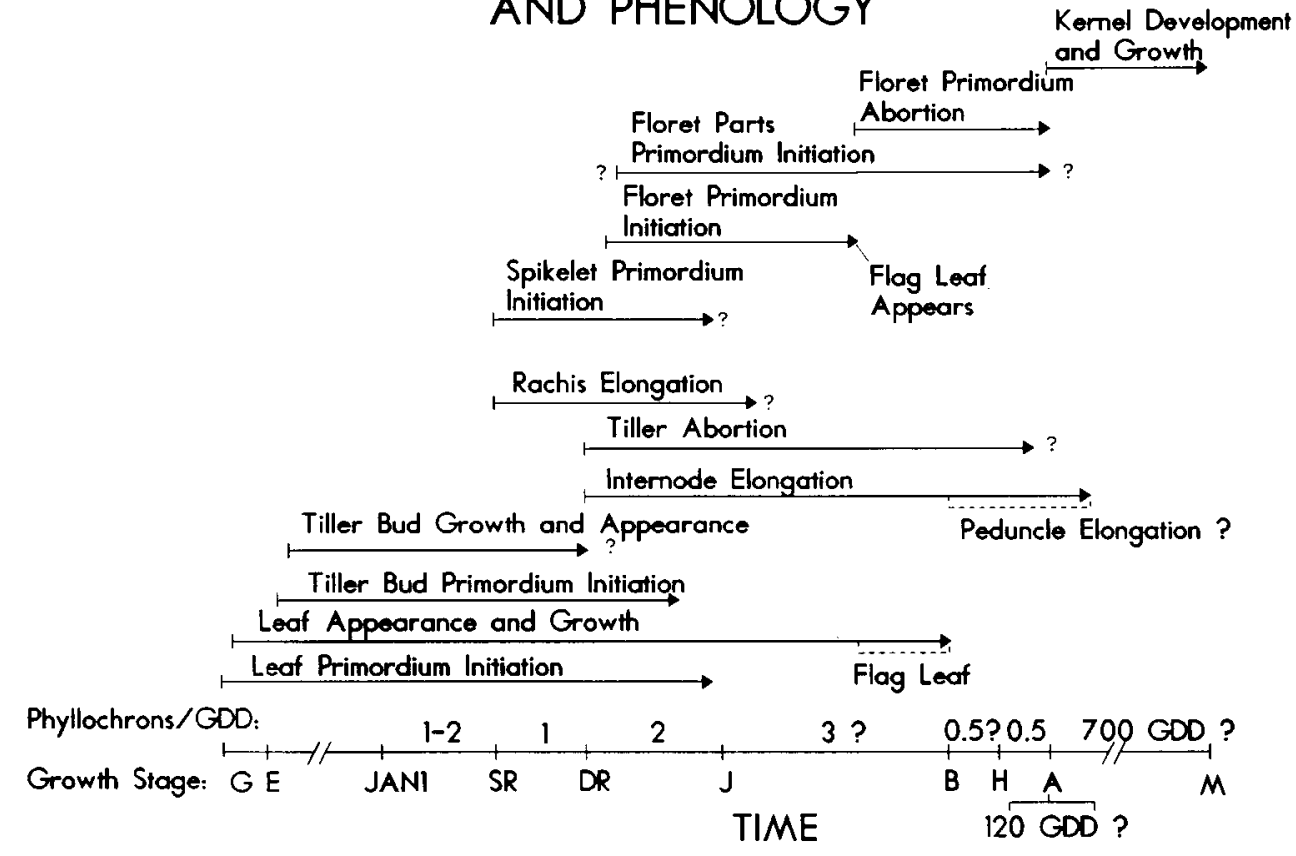

and Growth

Fig. 1. Developmental sequence of the shoot apex correlated with phenological growth stages: germination $(G)$, seedling emergence $(E)$, single ridge (SR), double ridge (DR), jointing (J), booting (B), heading $(\mathrm{H})$, anthesis (A), and physiological maturity (M). Leaf appearance is the time when the youngest expanding lamina can be seen emerging from the enclosing penultimate leaf. Question marks indicate areas of uncertainty or variability due to cultivars, environment, or conflicting reports in the literature. 
Several modifications were needed to incorporate SPIKEGRO into SHOOTGRO 2.0. If non-stressed spike development and growth is desired, then resource availability indices are set to 1.0 , which equals no stress. The user may choose the stress or no-stress option at the beginning of the simulation.

A major change was made in the phenology submodel, which simulates the day specific growth stages occur. SPIKEGRO incorporates many other growth stages (Fig. 1) for each culm in each age class than does SHOOTGRO, and predicts most of them with a phyllochron approach. The Haun (Haun, 1973), Feekes (Large, 1954), and Zadoks-Chang-Konzak (Zadoks et al., 1974) phenological growth stage scales are designated in SPIKEGRO, and equivalent stages between the Feekes and Zadoks et al. scales are estimated.

The internode growth submodel in SHOOTGRO was extended to incorporate peduncle elongation. Necessary conceptual modifications are discussed in the Peduncle Growth Submodel section later.

\section{SPIKEGRO SUBMODELS}

SPIKEGRO is organized by submodels (Fig. 2). The Seedling Emergence and Phyllochron submodels are called at the beginning of the simulation. Thirteen of the remaining submodels, normally called each day, are grouped within two general disciplines: growth and morphology. Submodels marked with asterisks denote new or significantly modified submodels added to SHOOTGRO, resulting in SPIKEGRO, and the remainder of this manuscript describes these submodels.

\section{Phenology submodel}

Figure 1 illustrates the developmental sequence of the winter wheat shoot apex, except the initiation and growth of floret parts, derived from the literature and personal research. The developmental sequence is correlated with phenological stages such as germination $(G)$, seedling emergence $(E)$, single and double ridge (SR, DR), jointing $(\mathrm{J})$, booting $(\mathrm{B})$, heating $(\mathrm{H})$, anthesis (A), and physiological maturity (M). Question marks delineate areas of uncertainty owing to (1) cultivar variation, (2) lack of data, or (3) conflicting or variable reports in the literature.

The phyllochron is used as the measure of thermal time for most developmental events, rather than accumulated GDD. If thermal time is measured in GDD, then the phyllochron is the same as the GDD model, but more flexible. Varying rates of winter wheat plant development observed in the field for different planting dates and latitudes (e.g. Nuttonson, 1948; Hay and Wilson, 1982; Kirby et al., 1982; Crofts et al., 1984; Battan and Khan, 1987; Kirby and Perry, 1987) are correctly predicted using the algorithm from Baker et al. (1980). This results in the phyllochron approach being more dynamic than the 


\section{SPIKEGRO SUBMODELS}

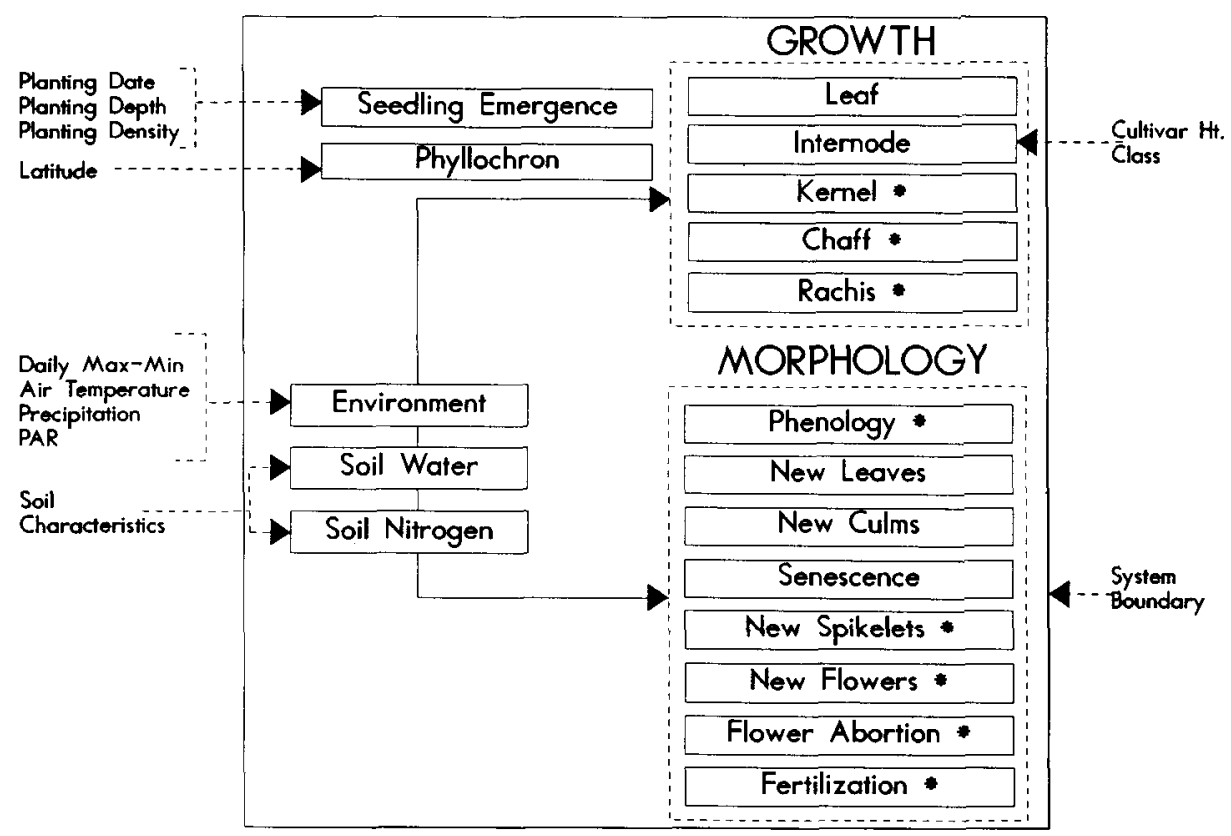

Fig. 2. SPIKEGRO submodels. Driving variables and initial inputs are listed outside of the system boundary box. Broken lines indicate submodels where these inputs have greatest or most direct effects. Asterisks denote new or significantly changed submodels added to SHOOTGRO, resulting in SPIKEGRO.

static GDD approach. A detailed discussion of the Phenology Submodel conceptualization and evaluation is presented in McMaster et al. (1990), McMaster (1991) and McMaster et al. (1992). McMaster (1991) re-calibrates some of the thermal line estimates presented in Fig. 1 for various soil water levels.

\section{Spikelet primordium initiation submodel}

Double ridge is the earliest possible time to visually discern formation of spikelets. However, by DR stage, about half of the final number of spikelet primordia have already been initiated (Baker and Gallagher, 1983a; Kirby, 1985). Thus, spikelet primordium initiation actually begins prior to the visually-observed DR stage. Other work shows percentage of spikelet primordia present at DR stage ranging from 9 to $80 \%$ of the final number. The actual number is difficult to determine, in part because of imprecise definitions of DR, and because DR stage may be a function of cultivar variation in the number of single ridges established and of the length of the transition phase from vegetative to reproductive primordium initiation. Fisher (1973) reported 
that semi-dwarf cultivars derived from Norin 10 tended to have a longer transition period and produce many more single ridges than standard-height cultivars.

Single ridge is the stage when the apex first elongates, with subsequent leaf primordia ceasing further development and forming a single ridge around the apex (Williams, 1966b; Fisher, 1973). The tissue between the single ridges develops into the spikelet primordium, resulting in the DR stage.

Baker and Gallagher (1983a) reported that the terminal spikelet primordium was formed just prior to J. Spikelet primordium initiation is simulated on each spike for each cohort. SPIKEGRO assumes that spikelet primordia begin to differentiate at the SR stage. The terminal spikelet is formed when the culm first reaches $J$ stage, thus ending spikelet primordium initiation for that spike.

Spikelet primordia are initiated acropetally on the shoot apex (Barnard, 1955; Bonnett, 1966; Kirby, 1974), and are initiated about three to four times faster than leaf primordia (Kirby, 1974; Baker and Gallagher, 1983a,b; Malvoisin, 1984). Photoperiod and light intensity may have some effects on spikelet primordium initiation (Friend, 1965a; Baker and Gallagher, 1983b; Kirby, 1985), but the effects are not well understood or quantified and vary widely with cultivars. Water and $\mathrm{N}$ do not seem to have much effect on spikelet primordium initiation rates (Whingwiri and Stern, 1982; Baker and Gallagher, 1983a), so presumably it is the duration of spikelet initiation that is affected by water and N. A linear rate of spikelet primordium initiation with GDD was reported by Malvoisin (1984) and Baker and Gallagher (1983b).

Temperature drives the rate of spikelet primordium initiation in SPIKEGRO. As in the entire SPIKEGRO model, temperature is represented as GDD with a $0^{\circ} \mathrm{C}$ base temperature. SPIKEGRO assumes a constant spikelet primordium initiation rate per phyllochron (SPIRATE)

SPIRATE $=\frac{\text { MAXSPIKELETS }}{\text { NOPCHRONS }}$

where MAXSPIKELETS is the maximum number of spikelets observed for the cultivar being simulated, and NOPCHRONS is the number of phyllochrons for the interval from SR to J. The user inputs SPIRATE if the default value ( 7.7 spikelets per phyllochron) is not desired. This default value is based on the largest number of spikelets per spike observed in the greenhouse, 23 (McMaster, 1991), divided by the thermal interval of three phyllochrons (the duration of spikelet primordium initiation, Fig. 1). Other potential default values are 8.1 (Malvoisin, 1984) and 6.3 (Kirby, 1974 for a spring wheat) spikelets per phyllochron, or about 0.07 spikelet primordia per day per ${ }^{\circ} \mathrm{C}(7.4$ spikelets per phyllochron if the phyllochron was $105 \mathrm{GDD}$ in his data) from Kirby (1985). SPIKEGRO currently allows a maximum of 30 spikelets per spike (Allison and Daynard, 1976). All culms are assumed to have the same spikelet primordium initiation rate. 
If one assumes a 3-phyllochron interval from SR to $\mathbf{J}$ stages for spikelet primordium initiation, a 1-phyllochron interval from SR to DR stages, and a constant spikelet primordium initiation rate, then one third of the final number of spikelets will have been initiated when DR stage is reached. This value falls within the range of $25-60 \%$ of the final number of spikelets present at DR stage reported (Baker and Gallagher, 1983a; Kirby, 1985).

\section{Spikelet differentiation submodel}

Spikelet differentiation is divided into floret primordium initiation and floret primordium abortion. Floret primordium initiation begins shortly after DR stage or the start of internode elongation (Kirby, 1974, 1985; Whingwiri and Stern, 1982; Baker and Gallagher, 1983a). SPIKEGRO begins simulation of floret primordium initiation after a $1 / 3$ phyllochron interval following DR stage and stops with flag leaf insertion (Kirby, 1988). When floret primordium initiation stops, floret promordium abortion commences and continues until the onset of anthesis for that culm (Kirby, 1985, 1988).

Spikelet differentiation begins in spikelets that, at maturity, are positioned in the central region of the spike (e.g. Barnard, 1955; Bonnett, 1966; Williams, 1966a; Fisher, 1973). Differentiation proceeds acropetally within a spikelet and acropetally and basipetally along the rachis. These processes occur simultaneously.

When spikelet differentiation begins, about half of the final number of spikelet initials are present on the shoot apex (Fig. 3). In SPIKEGRO, the penultimate spikelet primordium present at a $1 / 3$ phyllochron interval past DR stage is the first spikelet to begin differentiation. Each day that one or more spikelet primordia are initiated, the same number of basal florets in spikelets are initiated above and below the spikelets that have begun spikelet differentiation.

The variable controlling spikelet differentiation is temperature (GDD with a $0^{\circ} \mathrm{C}$ base temperature). It is assumed that water and $\mathrm{N}$ have no effect on spikelet differentiation rates (Whingwiri and Stern, 1982).

SPIKEGRO assumes a constant rate of floret primordium initiation within a spikelet driven by GDD. SPIKEGRO also assumes that all spikelets, spikes, and age classes have the same linear rate of floret primordium initiation (Kirby, 1974). The following assumptions were made to determine the rate of floret primordium initiation. A maximum of ten floret primordia can be produced on a central spikelet, although less than half of the florets are fertile at anthesis because of abortion or insufficient development (Bernard, 1955; Single, 1964; Evans et al., 1972; Langer and Hanif, 1973; Kirby, 1974, 1985, 1988; Whingwiri and Stern, 1982). The period from a $1 / 3$ phyllochron interval after DR stage to flag leaf appearance is a maximum of 3.7 phyllochrons. If the phyllochron is 105 GDD duration (McMaster, 1991), then there are about 


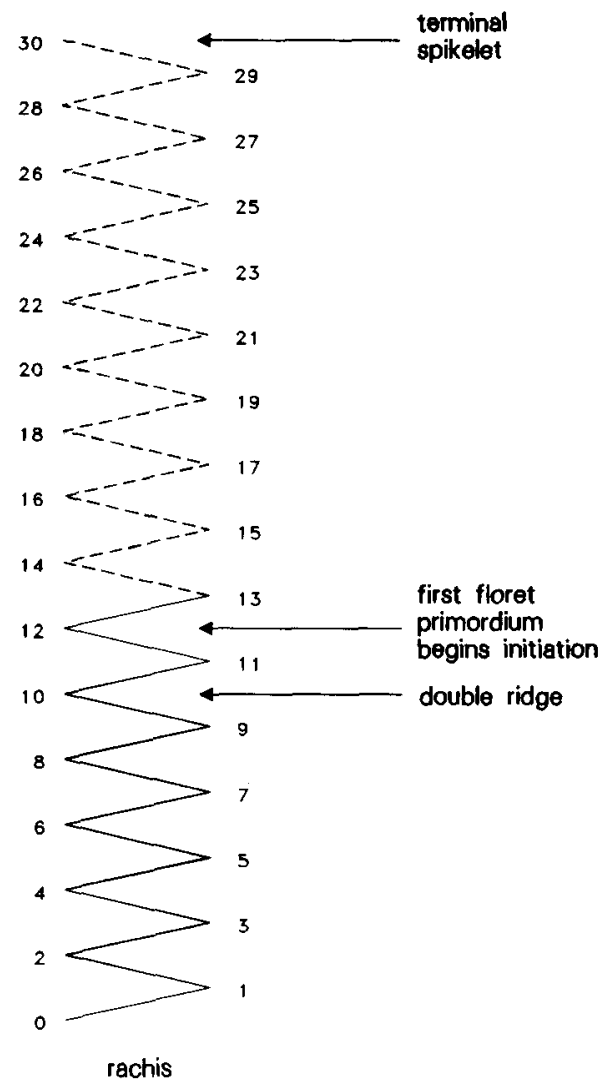

Fig. 3. Timing of spikelet primordium initiation within a spike. Correlation with other developmental events in SPIKEGRO are noted. Dashed line denotes spikelet primordia that have not been initiated.

385 GDD during this interval. Therefore, about 38.5 GDD are required for a new floret primordium to be initiated within a spikelet. This means that a new floret primordium is produced about every 0.37 phyllochrons, or that 2.7 floret primordia are initiated per phyllochron. SPIKEGRO uses 2.7 floret primordia initiated per phyllochron as a default value, but the user may change this number in the input parameter file.

Average daily temperatures above $30^{\circ} \mathrm{C}$ cause complete sterility for many reasons (Owen, 1971; Saini and Aspinall, 1982), so SPIKEGRO does not initiate floret primordia if the average daily temperature is greater than $30^{\circ} \mathrm{C}$. Any average daily temperature greater than $30^{\circ} \mathrm{C}$ is disregarded in accumulating GDD for spikelet differentiation.

In SPIKEGRO, all spikelets on a culm begin aborting floret primordia when the flag leaf appears; all spikelets cease floret primordia abortion when the culm reaches anthesis. Floret primordium abortion is also assumed to be 
a linear function of GDD with $0^{\circ} \mathrm{C}$ base temperature. In SPIKEGRO, the floret primordia abortion rate within a spikelet was estimated from the following assumptions: (1) the central spikelet reduces the ten floret primordia initiated to five viable florets at anthesis and (2) there is a 2-phyllochron interval from flag leaf appearance to anthesis. This results in 2.5 floret primordia aborting per phyllochron. This can be changed by the user in the parameter input file if desired. SPIKEGRO assumes a constant rate of floret primordium initiation and abortion for all spikelet positions within all spikes.

\section{Fertilization and grain set submodel}

Ovule fertilization follows pollination, and the first ovules are fertilized a few hours prior to the growth stage of anthesis (Martin et al., 1976; Herzog, 1986). SPIKEGRO assumes fertilization occurs during anthesis.

The duration of anthesis is based on GDD, with a $0^{\circ} \mathrm{C}$ base temperature, and is an input entered by the user. The default is $120 \mathrm{GDD}$, a duration of 6 days at an average daily temperature of $20^{\circ} \mathrm{C}$, and is based on unpublished greenhouse data of G.S. McMaster $(1988,1989)$. Rawson and Evans (1970), under controlled conditions, reported a 4 day interval (66 GDD) between the basal and fourth floret within a central spikelet reaching anthesis. Anthers appeared in the first florets about 5-6 days before appearing in the last florets (Rawson and Evans, 1970). SPIKEGRO assumes the duration of anthesis is the same for all spikes of all age classes.

The fertilization pattern within a spike follows the spikelet differentiation pattern, and occurs quite rapidly. Fertilization begins in basal florets in centrally located spikelets within the spike and occurs acropetally within the spikelet and acropetally and basipetally among spikelets beginning in the central region (Bonnett, 1966; Rawson and Evans, 1970; Oosterhuis, 1977). Ovule fertilization is controlled primarily by temperature. Fertilization of the basal floret in spikelets is simulated similarly to spikelet differentiation, except that groups of five spikelets have their basal florets fertilized simultaneously (Fig. 4). If it is given that (1) the maximum potential number of spikelets per spike is $30,(2)$ duration of anthesis is $120 \mathrm{GDD}$, and (3) 5 spikelets begin fertilization every 20 GDD (default value), then all spikelets have the potential of at least one fertilized floret by the end of anthesis.

Fertilization rate within a spikelet is assumed to be linearly related to GDD, and is determined by the duration of anthesis (ANTDUR) and the maximum number of florets that are sufficiently developed to be fertilized in the central spikelets (MAXFLORETS)

$$
\text { FERTRATE }=\frac{\text { ANTDUR }}{\text { MAXFLORETS }}
$$

If the default values of 120 GDD for ANTDUR and six florets for MAX- 


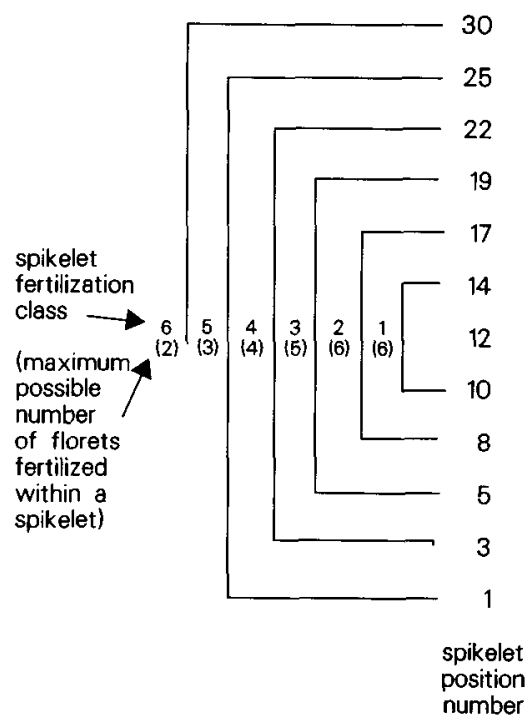

Fig. 4. Floret fertilization pattern within a spike. For illustrative purposes, fertilization begins in spikelet position 12. Assumes anthesis duration is 120 growing degree-days (GDD), the basal floret in five spikelets is fertilized every $20 \mathrm{GDD}$, and subsequent florets within a spikelet are fertilized every $20 \mathrm{GDD}$. The spikelet fertilization class (1 through 6) refers to the group of basal florets that will be fertilized simultaneously. Beneath the spikelet fertilization class, the maximum possible number of florets within a spikelet that can be fertilized is given inside parentheses.

FLORETS are used, then FERTRATE is 20 GDD per floret and will fertilize all florets within a central spikelet.

Average daily temperatures greater than $35^{\circ} \mathrm{C}$ prevent fertilization that day by ignoring temperatures greater than $35^{\circ} \mathrm{C}$ when accumulating GDD for fertilization. Such temperatures result in the fertilization of fewer florets. Water and $\mathrm{N}$ seem to have little effect on fertilization (Single, 1964), but grain set is affected, so that if the combined water and $\mathrm{N}$ resource availability index drops below 0.4 , fertilization does not occur that day. It is assumed that if an ovule is fertilized, then it will set a kernel. However, if resources are sufficiently limiting, little kernel growth may occur.

\section{Kernel growth submodel}

In SPIKEGRO, all kernels on all spikes of all age classes are simulated. At the beginning of the simulation, the user inputs estimates of final maximum potential kernel weight and duration of kernel growth for at least two average temperatures during kernel growth. It has been ubiquitously reported that as temperature increases, the duration of grain-filling decreases and kernel growth rates increase, with the net effect being smaller final kernel weights at higher temperatures (e.g. Bhuller and Jenner, 1983; Sayed and Ghondorah, 
1984; Spiertz and Vos, 1985; Vos, 1985; Herzog, 1986). Therefore, it is recommended that the input data reflect this relationship. The user chooses either a linear or log-linear curve fitting to the input data. In addition, the user can choose to break the relationship of final maximum potential kernel weight or duration of kernel growth or both with temperature into two separate curves, each part being either linear or log-linear. The last option is that an upper temperature breakpoint can be established where temperatures greater than or equal to the breakpoint have the same final maximum potential kernel weight and duration of grain-filling. A simple graph is shown on the terminal screen and printed to an output file showing the data that were input and the calculated curves so that the user can determine how well the input data fit the selected curve types and options.

Although the date of physiological maturity is affected by water and $\mathrm{N}$ availability (e.g. Angus and Moncur, 1977; Sionit et al., 1980; McMaster and Smika, 1988), few data are available to quantify the effects of water and $\mathrm{N}$ on duration of individual kernel growth. Therefore, SPIKEGRO simulates only temperature effects on the duration of individual grain-filling.

Daily individual kernel growth rate, in $\mathrm{mg} \mathrm{day}^{-1}$, is determined according to the following equation

Daily kernel growth rate $=(\mathrm{FWT} / \mathrm{DUR}) * \mathrm{DDO} * \mathrm{SINKST} * \mathrm{RAI}$

where FWT and DUR are the potential final kernel weight and duration of kernel growth, respectively, for a given temperature during the grain-filling period, DDO is the day's GDD with a $0^{\circ} \mathrm{C}$ base temperature, SINKST is the kernel sink strength factor, and RAI is the total resource availability index. SINKST and RAI are defined below.

Once FWT and DUR regressions are calculated for the input data, a running average daily temperature is estimated for each kernel beginning from the day of fertilization. The FWT and DUR values are determined as a function of running average temperature for that kernel to determine an individual kernel growth rate per GDD. The DDO for the current day is multiplied by the growth rate for that day to determine the potential increase in kernel weight for the day. Each kernel grows until the duration for that kernel had been completed, or until the culm reaches physiological maturity.

The estimated kernel dry weight increase is decreased by the sink strength factor (SINKST) and the total resource availability index (RAI). The sink strength of a kernel is set on the day of fertilization. Kernel sink strength is related to location in the spike, where kernels in central spikelets, or basal kernels within a spikelet, have greater sink strengths (Fig. 5, Rawson and Evans, 1970; Bremner, 1972). This pattern of sink strength positively correlates with the fertilization pattern. SPIKEGRO simulates sink strength as a function of time of fertilization. The first floret that is fertilized has a maximum strength of 1.0. The sink strength factor is decreased by 0.1 for each 


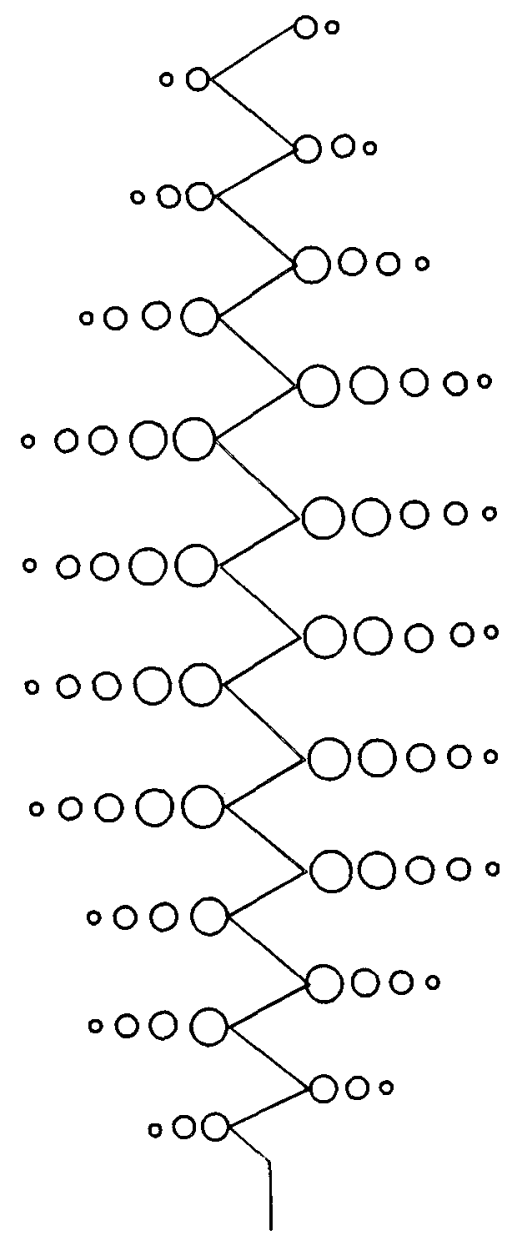

Fig. 5. Qualitative depiction of kernel sink strength relationships within a spike. The larger the circle diameter, the greater the sink strength (or potential growth rate).

day fertilization is delayed after Day 1 of fertilization. Although it appears that the second kernel from the base has slightly greater maximum potential growth rates than the basal kernel, under field or stressed conditions the actual growth rate is greater in the basal kernel (McMaster, 1991), and the SINKST factor will reflect this relationship between the two basal kernels.

The total resource availability index (RAI) is composed of running 5 day averages of the product of the water availability index and the $\mathrm{N}$ availability index. If sufficient $\mathrm{N}$ is available to meet the total demand for all growing organs, then the full potential growth is realized. If demand exceeds supply, then all plant parts are equally reduced so that the $N$ required for actual growth equals the available $\mathrm{N}$ from plant reserves and uptake. Allowing all 
shoot parts equal access to the available $\mathrm{N}$, rather than allowing kernels first priority, follows the data reported by McMaster et al. (1987).

\section{Peduncle growth submodel}

SPIKEGRO assumes the peduncle begins elongating at the boot stage, which begins about 3 phyllochrons after the culm reaches $\mathrm{J}$ stage. With 1 phyllochron period retained for internode elongation, the peduncle completes elongation at the onset of anthesis. Although some data suggest that peduncle elongation occurs into early grain-filling (Asana and Williams, 1965; Rawson and Evans, 1971; McMaster, 1991), SPIKEGRO assumes the peduncle completes elongation at anthesis. Peduncle elongation is simulated the same as all internodes in SHOOTGRO. The maximum potential length (which is a function of cultivar height-class) is divided by the phyllochron to estimate the daily extension per GDD. Maximum potential internode length is calculated according to the following equation

Maximum potential internode length $=10.89(\mathrm{~s})(n)^{1.73}$

where $\mathrm{s}$ is a constant related to a given cultivar height class (e.g. dwarf $=0.9$, semi-dwarf $=1.0$, mid-tall $=1.2$, tall $=1.4$ ) and $n$ ranges from 1 to 7 , where 7 refers to the internode associated with the flag leaf (i.e. the peduncle). As in SHOOTGRO, if insufficient water or $\mathrm{N}$ is available to allow maximum elongation, elongation is reduced by the resource availability index. The current daily GDD is used to calculate the elongation of the peduncle for a given day. The equation results in maximum peduncle lengths of $284 \mathrm{~mm}$ for dwarf, $316 \mathrm{~mm}$ for semi-dwarf, $379 \mathrm{~mm}$ for mid-tall, and $442 \mathrm{~mm}$ for tall cultivars. For Vona, a semi-dwarf, the largest observed peduncle length of $276 \mathrm{~mm}$ in the greenhouse (McMaster, 1991) agrees well with the predicted $316 \mathrm{~mm}$. The same specific culm weight $\left(1.5 \mathrm{~g} \mathrm{~m}^{-1}\right)$ is used for converting peduncle length to weight as for the other internodes. McMaster (1991) reports specific culm weights for peduncles for two cultivars under greenhouse conditions ranging from 1.0 to $2.4 \mathrm{~g} \mathrm{~m}^{-1}$, with almost all values less than 2.0 .

\section{Rachis growth submodel}

Rachis internode extension coincides with spikelet formation for spring wheat (Holmes, 1973). Negligible rachis elongation ( $<$ about $2 \mathrm{~mm}$ ) occurs after anthesis (McMaster, 1991). However, when rachis elongation ceases is unknown. With timing based on the data of Holmes (1973), rachis elongation begins in SPIKEGRO at DR stage and ends at $\mathbf{J}$ stage. This interval coincides with spikelet formation, if one assumes spikelet formation begins at DR stage when the spikelet primordia are first readily discernible.

Singh and Singh (1985) found spike lengths of about $103 \mathrm{~mm}$ and rachis 
weights of about $65 \mathrm{mg}$ for four cultivars under various treatments, while McMaster (1991) reported maximum lengths of $85 \mathrm{~mm}$ and weights of $83.6 \mathrm{mg}$ (for two cultivars, Vona and Bezostaya) under greenhouse conditions. Spikes elongate linearly over time (Mishra and Mohapatra, 1987). If one assumes a final rachis length of $100 \mathrm{~mm}$, duration of rachis elongation of two phyllochrons, a phyllochron of 105 GDD, and a linear growth rate, then a rachis elongation rate of $0.48 \mathrm{~mm} \mathrm{GDD}^{-1}$ is expected. Kirby (1988) reported a rate of $0.51 \mathrm{~mm} \mathrm{GDD}^{-1}$. Singh and Singh (1985) reported a final spike length of $103 \mathrm{~mm}$, giving an elongation rate of $0.45 \mathrm{~mm} \mathrm{GDD}^{-1}$, while data from McMaster (1991) gives an elongation rate of $0.43 \mathrm{~mm} \mathrm{GDD}-1$.

Rachis elongation is calculated each day for each rachis for all cohorts. The potential rachis elongation rate $\left(\mathrm{mm} \mathrm{GDD}^{-1}, 0^{\circ} \mathrm{C}\right.$ base temperature) is determined by dividing the maximum potential final rachis length (MAXPL) by the thermal time interval for the duration of growth (NOPCHRONS)

\section{PRACHISL $=\frac{\text { MAXPL }}{\text { NOPCHRONS }}$}

The default value for MAXPL is $100 \mathrm{~mm}$ and NOPCHRONS is 2 phyllochrons, which gives a potential elongation rate of $0.48 \mathrm{~mm}$ per degree-day (assuming a phyllochron of $105 \mathrm{GDD}$ ). The default value can be changed by the user. The potential elongation rate per degree-day is multiplied by each day's degree-days (DDO) to obtain the daily maximum potential elongation. The maximum potential elongation is reduced by the resource availability index factor (RAI) to get the actual daily elongation rate (DERATE)

\section{DERATE $=($ PRACHISL $)(D D O)($ RAI $)$}

SPIKEGRO assumes that all culms have spikes of equal final length. This assumption is satisfactory in most situations for the MS, T1, and T2 culms because these culms tend to produce a similar number of spikelets (McMaster, 1991). However, for culms that normally produce fewer spikelets per spike, the assumption is less valid but viewed as an insignificant problem. The rachis length is converted to weight by multiplying the length by the specific rachis weight of $1.5 \mathrm{~g} \mathrm{~m}^{-1}$ derived from greenhouse data where all cultivars and culms were combined.

\section{Chaff growth submodel}

Chaff is composed of glumes, paleas, lemmas, rachillas, and often rachises. Chaff differentiation and growth begins shortly after the spikelet begins differentiation, which SPIKEGRO sets at $1 / 3$ phyllochron after DR stage. Development of floret parts ceases by anthesis, if not before (McMaster, 1991). Asana and Williams (1965) found that chaff weight did not increase after 12 days past anthesis (about 385 GDD). 
Chaff weight is highly variable among cultivars and years. Cultivars with awns often seem to have greater chaff weight. Yet, cultivars are often neither completely awnless nor awned. Cultivar Vona, for instance, tends not to have awns on lemmas of the lowermost spikelets (G.S. McMaster, personal observations, 1985-1992), and Gabo has short tip awns in the apical three or four spikelets (Single, 1964). Miller (1939) shows that chaff dry weight at harvest for two cultivars was about 37 and $54 \%$ of grain weight for 2 different years, and that both cultivars had similar percentages within a year. Asana and Williams (1965) found chaff weight for the main stem to be 5.9 and $9.1 \%$ of the chaff plus grain weight for two cultivars. Bingham (1967) found that glume weight was between 16 and $21 \%$ of grain weight for three cultivars and that irrigation significantly increased glume weight, but that $\mathrm{N}$ had no significant effect. For Gabo, N strongly influenced awn weight, with awn weight per spike ranging from 2 to $22 \mathrm{mg}$ per spike (Single, 1964). McMaster (1991) reported chaff weights ranging from 18.3 to $29.2 \%$ of total spike weight when grown in the greenhouse.

In SPIKEGRO, chaff weight is comprised of glumes, paleas, lemmas, awns, and rachillas; the rachis is not considered chaff and is simulated in the Rachis Growth submodel. It is assumed that chaff weight is negligible until after floret primordium initiation begins ( $1 / 3$ of a phyllochron interval past DR stage), so SPIKEGRO starts chaff growth 0.5 phyllochron after DR stage begins. Chaff growth stops when grain-filling is $50 \%$ completed. If the default of $700 \mathrm{GDD}$ is used for the duration of grain-filling (as used in the phenology submodel for the duration of all kernels for grain-filling), then the duration of chaff growth is 5.5 phyllochrons plus 350 GDD. A phyllochron of 105 GDD results in a duration of chaff growth of 930 GDD.

A linear growth rate is assumed with temperature. The potential growth rate per degree-day (PCHAFFW) is calculated by dividing the maximum final potential chaff weight (MAXPW) by the duration of chaff growth (CHAFFDUR)

$$
\text { PCHAFFW }=\frac{\text { MAXPW }}{\text { CHAFFDUR }}
$$

The default value for MAXPW is $450 \mathrm{mg} \mathrm{spike}^{-1}$ (McMaster, 1991), but can be changed by the user in the input parameter file. If a duration of $930 \mathrm{GDD}$ and final weight of $450 \mathrm{mg}^{-1}$ spike $^{-1}$ is assumed, chaff weight will potentially increase by $0.48 \mathrm{mg} \mathrm{GDD}^{-1}\left(0^{\circ} \mathrm{C}\right.$ base temperature $)$. The actual daily increase in chaff weight (DICHAFFW) is obtained by multiplying the growth rate per GDD (PCHAFFW), the current day's GDD (DDO), and the resource availability index (RAI)

\section{DICHAFFW $=($ PSCHAFFW $)(\mathrm{DDO})(\mathrm{RAI})$}

As with rachis length, chaff weight growth rates are equal for all culms. 


\section{MODEL EVALUATION}

\section{Validation and sensitivity analysis data sets}

Evaluation of SPIKEGRO consisted of validation of the submodels and sensitivity analysis. Three main data sets were used in the submodel validation and sensitivity analysis. (1) A field experiment testing irrigation scheduling on winter wheat (cultivar Vona) growth and development was conducted for two growing seasons beginning in fall 1986 at the Colorado State University Horticulture Farm in Fort Collins, CO (McMaster, 1991). Detailed measurements of dimensions and weights of internodes, blades, sheaths, kernels, rachises, and chaff were periodically taken on morphologically identified culms. This data set provided most of the detailed validation data for many of the SPIKEGRO submodels dealing with primordia initiation and growth. (2) A field experiment was conducted in 1981-1982 where the effects of shading on shoot and spike growth and morphology were tested (McMaster et al., 1987). (3) The phenology submodel was evaluated by using a data set covering 19 site-years across the Central Great Plains from 1977 to 1981 (McMaster and Smika, 1988). Other additional field studies were occasionally used to validate specific submodels (e.g., Haley, 1989; Mujahid, 1989; McMaster et al., 1991).

In all of these validation data sets, not all initial conditions were known or gaps in the weather data were present or both. Best estimates were made, but clearly some unknowns such as initial soil water content and stand density have large impacts on model performance. Initial conditions used for the soil profile are given in McMaster (1991).

\section{Submodel validation}

The phyllochron is a fundamental concept used throughout all SPIKEGRO submodels. To evaluate the validity of the Baker et al. (1980) algorithm, the phyllochron for ten cultivars (Agate, Baca, Bezostaya, Centurk 78, Century, Chisholm, Stephens, Sturdy, Tam 101, and Vona) were measured on 31 December, 1986 after planting in September at the CSU Horticulture Farm. The mean observed phyllochron was 106.9 GDD. The simulated phyllochron was $108.5 \mathrm{GDD}$, which agreed very well with the observed.

Validation results of the phenology submodel are presented elsewhere (McMaster, 1991; McMaster et al., 1990, 1992), but the overall results were as follows. For the 19 site-years, the mean observed and simulated day of seedling emergence, heading, and maturity were the same (23 September, 1 June, and 6 July, respectively). Jointing was simulated 3 days late on the average (4 May instead of 1 May). The range of differences between the observed and simulated day of seedling emergence was -3 to 6 days, for 


\section{TABLE 1}

Observed and simulated number of spikelets by culm. MS denotes main stem; T1 and T2 are primary tillers using the naming scheme of Klepper et al. (1983). Total number of spikelets for a culm are the total number of spikelet primordia that were initiated; fertile spikelets are those spikelets that have at least one kernel present in the spikelet at maturity. Observed data are from a 2 year experiment at the Colorado State University Horticulture Farm. The 1986-1987 data are from the N + late-jointing irrigation treatment; the 1987-1988 data are from the late-jointing + anthesis irrigation treatment

\begin{tabular}{|c|c|c|c|c|c|c|}
\hline & \multicolumn{6}{|c|}{ Spikelets culm ${ }^{-1}$} \\
\hline & \multicolumn{2}{|l|}{ MS } & \multicolumn{2}{|l|}{$\mathrm{T} 1$} & \multicolumn{2}{|l|}{$\mathrm{T} 2$} \\
\hline & OBS & SIM & OBS & SIM & OBS & SIM \\
\hline \multicolumn{7}{|l|}{$1986-1987$} \\
\hline Total no. spikelets & 19.0 & 22 & 17.9 & 22 & 16.9 & 22 \\
\hline No. fertile spikelets & 16.8 & 21 & 14.8 & 15 & 13.6 & 22 \\
\hline \multicolumn{7}{|l|}{1987} \\
\hline Total no. spikelets & 20.1 & 23 & 19.5 & 23 & 19.2 & 23 \\
\hline No. fertile spikelets & 18.6 & 9 & 17.5 & 22 & 17.0 & 19 \\
\hline
\end{tabular}

jointing was -24 to 19 days, for heading was -15 to 23 days, and for maturity was -10 to 20 days. Most simulated days fell within $2,10,8$, and 5 days of the observed day for reaching seedling emergence, jointing, heading, and maturity, respectively.

One validation of the spikelet primordium initiation submodel was to examine the total number of spikelet primordia initiated for the main stem (MS), T1, and T2 culms. The model over-predicted the number of spikelets initiated (Table 1). The observed data are for fairly high levels of $\mathrm{N}$ and water, although irrigation was not applied until late-jointing, after which spikelet primordia initiation had stopped. The over-prediction could be owing to (1) the duration of initiation is too long, especially since there is variability in when the terminal spikelet is initiated, (2) the rate of spikelet primordia initiation is too high, and (3) the availability of water and $\mathrm{N}$ should alter the initiation rate or duration of initiation.

The observed pattern of fewer spikelets per spike initiated on successively younger culms (Table 1) was not simulated since the model assumed the same rate of spikelet primordia initiation for all culms. A reduced rate based on the age of the culm would improve the accuracy of the spikelet initiation submodel. Then the tendency to over-predict the number of main stem spikelets per spike by about three spikelets per spike (Tables 1 and 2) would not be magnified into larger differences between simulated and observed for tillers.

We are unaware of any field data sets for evaluating floret primordia initiation and abortion and ovule fertilization pattern within a spike. Verifi- 
cation that the code produced our a priori expected pattern was done (results not shown).

The grain set within a spike can be evaluated by comparing the observed with simulated kernel pattern. The simulated number of kernels by spikelet position within main stem, $\mathrm{T} 1$, and $\mathrm{T} 2$ spikes generally tends to be higher, especially for central spikelets (Table 2; also the case for 1988, data not shown). Apical spikelets often tend to have more observed number of kernels per spikelet than is simulated, and the opposite tends to occur for basal spikelets (also the case for 1988, data not shown). The simulated spikelet with the highest number of kernels per spikelet generally was within one spikelet position of the observed spikelet position, suggesting that the model correctly began fertilization and kernel growth at the correct position within the spike. Since the simulated pattern of kernels per spikelet followed the observed, corrections to the rate and duration of fertilization of apical and basal spikelets would improve the submodel in predicting the number of kernels per spikelet, particularly in apical and basal spikelets, and thus number of fertile spikelets. Reducing tiller fertilization rates by age of tiller would result in a better relationship between the observed and simulated number of fertile spikelets (Table 1).

The simulated mean individual kernel weight per spikelet generally was similar to the observed. For $1982 \mathrm{MS}$, the simulated weights were lower, and for 1987 and 1988 (1988 data not shown) the simulated weights were higher than the observed (Table 2).

In comparing the observed final kernel weights by position within a spikelet, for both 1987 and 1988, the observed kernel weights for the first two kernel positions within a spikelet always were very similar (Table 3). The third kernel was always significantly smaller than the first two kernels, and each successive kernel was smaller than the preceding kernel. The algorithm used in SPIKEGRO decreased kernel sink strength (i.e. decrease potential growth rates) by $10 \%$ for each day's delay from the onset of fertilization. This simplified algorithm resulted in the first kernel always being heavier than the second kernel, and an essentially linear decrease in weight of successive kernels within a spikelet. The first kernel position always had greater simulated weight than observed, and usually the simulated weight for kernels in Position 2 also were higher than observed. This could be due to incorrect input curves determining the duration of kernel growth and final kernel weight for given temperatures during grain-filling for the cultivars simulated, or insufficient reductions of kernel growth owing to water and $\mathrm{N}$ stresses, or both.

The model simulated greater rachis lengths (about 25\% higher) and rachis weights (about $60 \%$ higher) than was observed in the CSU Horticulture Farm Experiment. The observed mean specific culm weight of $0.6 \mathrm{~g} \mathrm{~m}-2$ was much lower than the model value of $1.5 \mathrm{~g} \mathrm{~m}^{-2}$, resulting in the greater error between simulated and observed weights than lengths. Also, the input default of 


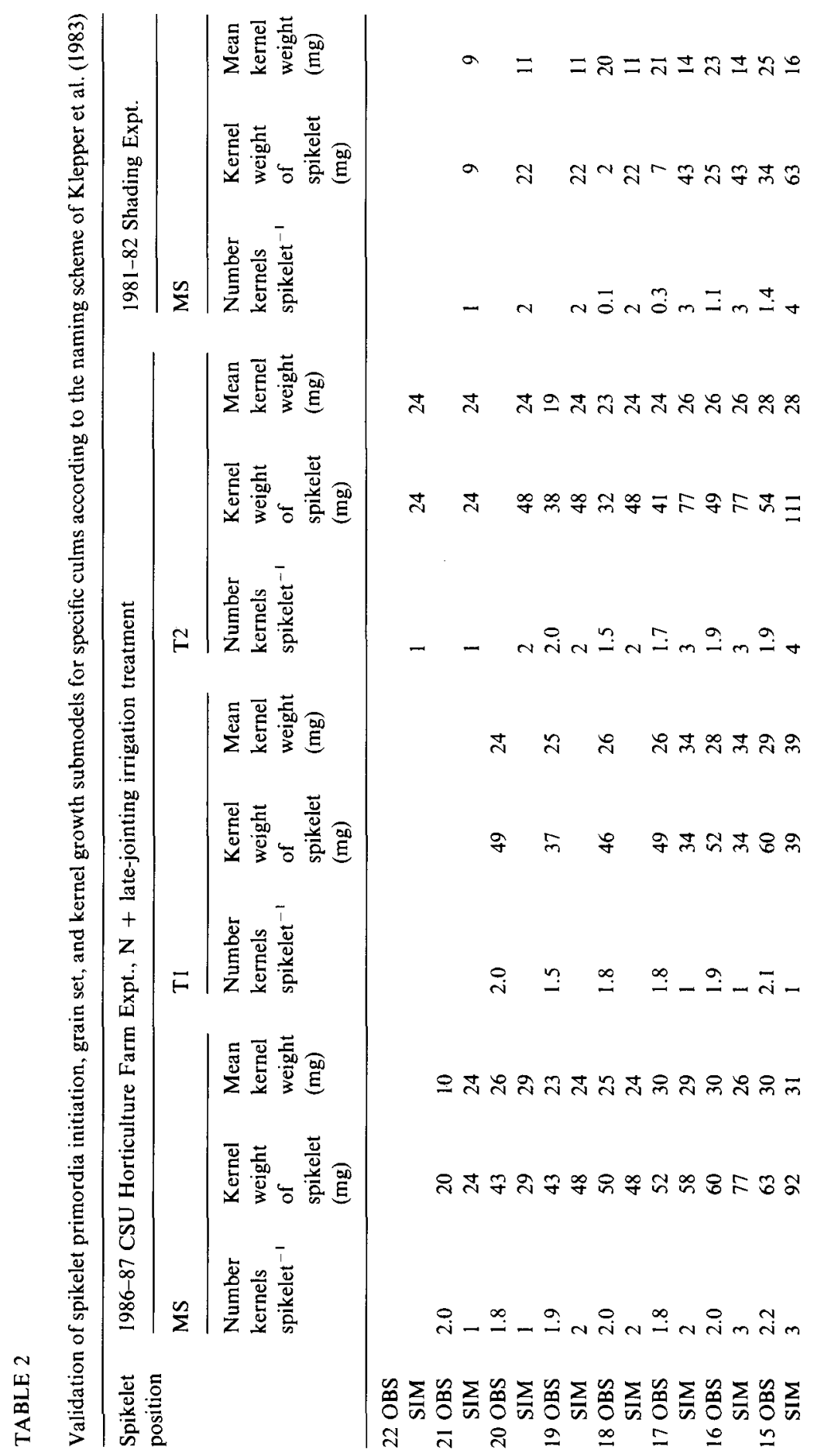




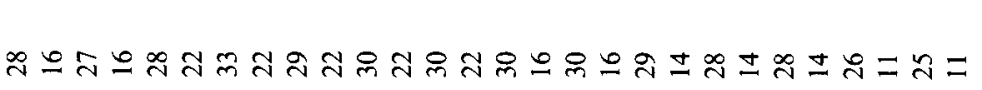
サ

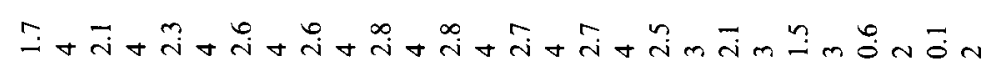

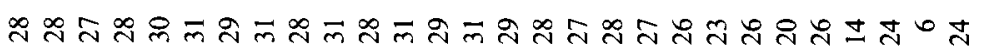

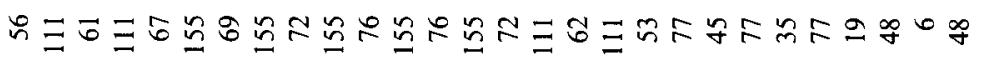

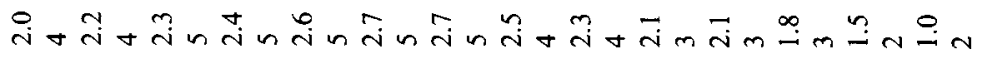

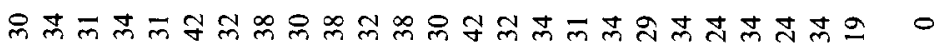

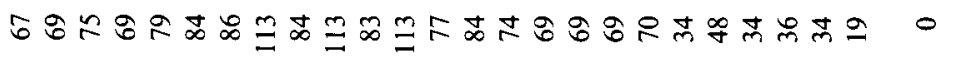

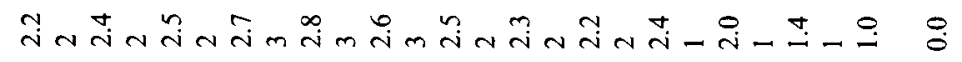

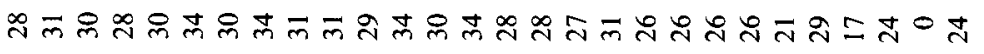

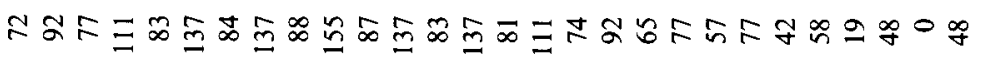

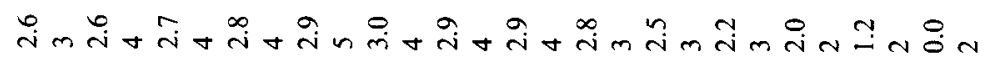

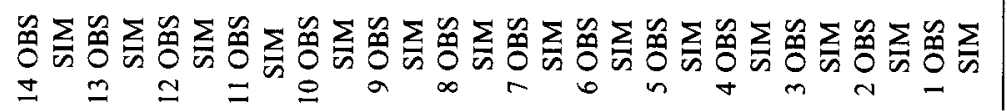




\section{TABLE 3}

Kernel weight within a spikelet by spikelet position within a spike. Apical, central, and basal spikelets are $80 \%, 50 \%$, and $20 \%$, respectively, above the base of the spike. Kernel position numbering is acropetally from the base of the rachilla. Observed data are from the Colorado State University Horticulture Experiment, where the N + late-jointing irrigation treatment is used in 1986-1987, and the late-jointing + anthesis irrigation treatment is used for 1987-1988

\begin{tabular}{|c|c|c|c|c|c|c|c|}
\hline \multirow{3}{*}{$\begin{array}{l}\text { Culm } \\
\text { ID }\end{array}$} & \multirow{3}{*}{$\begin{array}{l}\text { Kernel } \\
\text { position }\end{array}$} & \multicolumn{6}{|c|}{ Kernel weight (mg) } \\
\hline & & \multicolumn{2}{|c|}{ Apical } & \multicolumn{2}{|c|}{ Central } & \multicolumn{2}{|l|}{ Basal } \\
\hline & & OBS & SIM & OBS & SIM & OBS & SIM \\
\hline \multicolumn{8}{|c|}{$1986-1987$} \\
\hline \multirow[t]{5}{*}{ MS } & 1 & 31.8 & 34 & 33.0 & 45 & 26.3 & 34 \\
\hline & 2 & 31.8 & 24 & 32.9 & 39 & 27.4 & 24 \\
\hline & 3 & 9.9 & - & 22.6 & 29 & 21.5 & 18 \\
\hline & 4 & & & - & 24 & & \\
\hline & 5 & & & - & 18 & & \\
\hline \multirow[t]{3}{*}{$\mathrm{Tl}$} & 1 & 32.7 & 34 & 34.3 & 45 & 28.2 & 34 \\
\hline & 2 & 31.2 & - & 35.7 & 39 & 31.0 & - \\
\hline & 3 & 13.3 & - & 21.2 & 29 & 13.2 & - \\
\hline \multirow[t]{5}{*}{$\mathrm{T} 2$} & 1 & 29.7 & 39 & 31.8 & 45 & 23.5 & 34 \\
\hline & 2 & 27.4 & 29 & 33.0 & 39 & 21.6 & 24 \\
\hline & 3 & 12.1 & 24 & 14.8 & 29 & - & 18 \\
\hline & 4 & - & 18 & - & 24 & & \\
\hline & 5 & & & - & 18 & & \\
\hline \multicolumn{8}{|c|}{$1987-1988$} \\
\hline \multirow[t]{4}{*}{ MS } & 1 & 32.6 & - & 35.6 & 48 & 33.9 & - \\
\hline & 2 & 32.6 & - & 37.5 & 43 & 31.6 & - \\
\hline & 3 & 9.1 & - & 31.2 & - & 21.8 & - \\
\hline & 4 & & & 15.4 & - & & \\
\hline \multirow[t]{4}{*}{$\mathrm{Tl}$} & 1 & 30.9 & 33 & 34.1 & 48 & 27.9 & 38 \\
\hline & 2 & 31.3 & - & 35.4 & 43 & 35.1 & 33 \\
\hline & 3 & 13.3 & - & 29.2 & 33 & 26.1 & - \\
\hline & 4 & & & 15.7 & 27 & 24.2 & - \\
\hline \multirow[t]{4}{*}{$\mathrm{T} 2$} & 1 & 31.0 & 33 & 33.3 & 48 & 29.6 & 38 \\
\hline & 2 & 31.1 & - & 34.9 & 43 & 30.3 & - \\
\hline & 3 & 15.3 & - & 27.4 & 33 & 16.1 & - \\
\hline & 4 & & & 17.4 & - & & \\
\hline
\end{tabular}

$100 \mathrm{~mm}$ for maximum potential rachis length appears to be too high for the cultivars simulated.

Simulated and observed peduncle lengths were generally close, the mean difference being $43 \mathrm{~mm}$ (within 14\%). In 1987, the model over-predicted peduncle lengths, and in 1988 under-predicted. Because simulated peduncle lengths were close to the observed, but the simulated weights were much too high, the specific culm weight of $1.5 \mathrm{~g} \mathrm{~m}^{-2}$ is too great and needs to be reduced.

Simulated main stem chaff weights were close to the observed (mean 
difference of $56 \mathrm{mg}$, within 14\%), but because the model does not reduce chaff growth on tillers compared to the main stem under stress conditions, simulated chaff weight did not decrease on successively younger culms as was observed in the field.

\section{Sensitivity analysis}

A sensitivity analysis was conducted to determine the importance of specific parameters, initial inputs, driving variables, and algorithms by altering only one factor at a time and then assessing output variables such as yield, aboveground biomass, yield components, and phenology. Twenty site-years (18 from McMaster and Smika, 1988; 1986-1987 N + late-jointing irrigation treatment and 1987-1988 late-jointing + anthesis irrigation treatment from CSU Horticulture Farm Experiment) were run for each change. More complete results of the sensitivity analysis are given in McMaster (1991), but a summary follows.

SPIKEGRO was viewed as very sensitive to a change in the factor if most of the output variable means changed more than the factor was changed. Moderately sensitive was defined as an equal change in most of the output variable means to the change in the factor. Low sensitivity was defined as less change in output variable means than the factor was changed. The model was very sensitive to initial soil water content, air temperature, duration of floret primordium initiation, and two kernel growth parameters (kernel sink strength and final kernel weight for a given temperature). SPIKEGRO was moderately sensitive to changes in certain growth stage intervals (the intervals from double ridge to jointing, jointing to booting, the duration of anthesis, and the duration of grain-filling for a mean temperature), precipitation, planting density, and bulk density. The model had low sensitivity to all other factors tested.

\section{SPIKEGRO modifications}

Based on known initial simplifications, the validation results, and sensitivity analysis, the following modifications are suggested to improve the realism and predictions of SPIKEGRO: (1) a stagger among culms in reaching specific growth stages or developmental events; (2) incorporate water availability effects in the phenology submodel; (3) to simulate fewer spikelets, fertile spikelets, kernels, and kernel weights in tillers than main stems, a reduction in duration of growth stages is needed for tillers, which would be controlled by modification number 2 above; (4) the kernel sink strength algorithm needs to be changed so that the first two kernels have nearly the same sink strength; (5) careful attention needs to be paid to initial inputs such as the final kernel weight and duration of grain-filling for specific temperatures, and initial 
conditions such as soil water content; (6) more rigorous effort needs to be directed towards specific stress reduction algorithms on spikelet and floret initiation rates, fertilization pattern, and kernel, rachis and chaff growth.

\section{MODEL APPLICATIONS}

SPIKEGRO can be used as a research tool in a number of ways. For example, if optimal water and $\mathrm{N}$ levels are assumed in the simulation, the potential development and growth may be predicted and contrasted to simulations with field levels of water and $\mathbf{N}$ for the same climatic conditions. In this manner, the affects of water and $\mathrm{N}$ stress on the potential development and growth can be examined. Further analysis on the effects of individual stresses change can be conducted. By altering the timing and intensity of stresses, the affects on early development and growth can be studied for their ramifications later in the life-cycle, as well as how timing of stresses specifically affects shoot apex functioning and subsequent impacts. Germplasm selection could be aided by determining what set of 'traits' are optimal for particular climatic conditions, or how a trait might affect overall plant response.

Management strategies are increasingly being related to stage of crop development. The timing of the application of many herbicides and pesticides is specific to certain stages of shoot apex development, and optimum application of fertilizer and irrigation occurs when the crop is at a specific development stage. SPIKEGRO can aid managers in determining when the crop will reach a particular development stage, especially those stages that can be observed only after dissection and magnification.

\section{ACKNOWLEDGMENTS}

Special thanks goes to B. Kleppe and R.W. Rickman for many valuable discussions on wheat development and phenology, and to R. Anderson, A. Bauer, C. Grieve, and G. Maas for helpful reviews of this manuscript.

\section{REFERENCES}

Allison, J.C.S. and Daynard, T.B., 1976. Effect of photoperiod on development and number of spikelets of a temperate and some low-latitude wheats. Ann. Appl. Biol., 83: 93-102.

Angus, J.F. and Moncur, M.W., 1977. Water stress and phenology in wheat. Aust. J. Agric. Res., 28: $177-181$.

Asana, R.D. and Williams, R.F., 1965. The effect of temperature stress on grain development in wheat. Aust. J. Agric. Res., 16: 1-13.

Baker, C.K. and Gallagher, J.N., 1983a. The development of winter wheat in the field. 1. Relation between apical development and plant morphology within and between seasons. J. Agric. Sci., Camb., 101: 327-335.

Baker, C.K. and Gallagher, J.N., 1983b. The development of winter wheat in the field. 2. The control 
of primordium initiation rate by temperature and photoperiod. J. Agric. Sci., Camb., 101: 337-344.

Baker, C.K., Gallagher, J.N. and Monteith, J.L., 1980. Daylength change and leaf appearance in winter wheat. Plant, Cell, and Environ., 3: 285-287.

Baker, D.N., Whisler, F.D., Parton, W.J., Klepper, E.L., Cole, C.V., Willis, W.O., Smika, D.E., Black, A.L. and Bauer, A., 1985. The development of winter wheat: A physiological process model. In: W.O. Willis (Editor), ARS Wheat Yield Project. USDA, Agricultural Research Service ARS-38, pp. 176-187.

Baker, J.T., Pinter, P.J., Jr., Reginato, R.J. and Kanemasu, E.T., 1986. Effects of temperature on leaf appearance in spring and winter wheat cultivars. Agron. J., 78: 605-613.

Barnard, C., 1955. Histogenesis of the inflorescence and flower of Triticum aestivum L. Aust. J. Bot. 3: $1-24$.

Battan, G.D. and Khan, M.A., 1987. Effect of time of sowing on grain yield, and nutrient uptake of wheats with contrasting phenology. Aust. J. Exp. Agric., 27: 881-887.

Belford, R.K., Klepper, B. and Rickman, R.W., 1987. Studies of intact shoot-root systems of field-grown winter wheat. Il. Root and shoot developmental patterns as related to nitrogen fertilizer. Agron. J. 79: 310-319.

Bhullar, S.S. and Jenner, C.F., 1983. Responses to brief periods of elevated temperature in ears and grains of wheat. Aust. J. Plant Physiol., 10: 549-560.

Bingham, J., 1967. Investigations on the physiology of yield in winter wheat, by comparisons of varieties and by artificial variation in grain number per ear. J. Agric. Sci., Camb., 68: 411-422.

Bonnett, O.T., 1966. Inflorescences of maize, wheat, rye, barley, and oats: Their initiation and development. Illinois Agric. Exp. Sta. Bull., 721, 105 pp.

Bremner, P.M., 1972. Accumulation of dry matter and nitrogen by grains in different positions of the wheat ear as influenced by shading and defoliation. Aust. J. Biol. Sci., 25: 657-668.

Crofts, H.J., Gardner, W.K. and Velthuis, R.G., 1984. A phenological evaluation of wheat for South-Western Victoria. Aust. J. Agric. Res., 35: 521-528.

Delecolle, R., Couvreur, F., Pluchard, P. and Varlet-Grancher, C., 1985. About the leaf-daylength model under French conditions. In: W. Day and R.K. Atkin (Editors), Wheat Growth and Modelling. Plenum Press, New York. pp. 25-32.

Delecolle, R., Hay, R.K.M., Guerif, M., Pluchard, P. and Varlet-Grancher, C., 1989. A method of describing the progress of apical development in wheat, based on the time-course of organogenesis. Field Crops Res., 21: 147-160.

Evans, L.T., Bingham, J. and Roskams, M.A., 1972. The pattern of grain set within ears of wheat. Aust. J. Biol. Sci., 25: 1-8.

Fisher, J.E., 1973. Developmental morphology of the inflorescence in hexapoloid wheat cultivars with and without the cultivar Norin 10 in their ancestry. Can. J. Plant Sci. 53: 7-15.

Friend, D.J.C., 1965a. Ear length and spikelet number of wheat grown at different temperatures and light intensities. Can. J. Bot. 43: 345-353.

Friend, D.J.C., 1965b. Tillering and leaf production in wheat as affected by temperature and light intensity. Can. J. Bot. 43: 1063-1076.

Gallagher, J.N., 1979. Field studies of cereal leaf growth. I. Initiation and expansion in relation to temperature and ontogeny. J. Expt. Bot., 30: 625-636.

Gallagher, J.N., Biscoe, B.V. and Wallace, J.S., 1979. Field studies of cereal leaf growth. IV. Winter wheat leaf extension in relation to temperature and leaf water status. J. Expt. Bot., 30: 657-668.

Godwin, D.C. and Vlek, P.L.G., 1985. Simulation of nitrogen dynamics in wheat cropping systems. In: W. Day and R.K. Atkin (Editors), Wheat Growth and Modelling . Plenum Press, New York, pp. 311-332.

Haley, S., 1989. Variation among winter wheats for traits associated with drought resistance. M.S. thesis, Colorado State University, Fort Collins, CO, $113 \mathrm{pp}$.

Haun, J.R., 1973. Visual quantification of wheat development. Agron. J. 65: 116-119. 
Hay, R.K.M. and Wilson, E.T., 1982. Leaf appearance and extension in field-grown winter wheat plants: The importance of soil temperature during vegetative growth. J. Agric. Sci., Camb., 99: 403-410.

Herzog, H., 1986. Source and Sink During the Reproductive Period of Wheat. Development and its Regulation With Special Reference to Cytokinins. Paul Parey Sci., Berlin, $104 \mathrm{pp}$.

Holmes, D.P., 1973. Inflorescence development of semidwarf and standard height wheat cultivars in different photoperiod and nitrogen treatments. Can. J. Bot., 51: 941-956.

Kirby, E.J.M., 1974. Ear development in spring wheat. J. Agric. Sci., Camb., 82: 437-447.

Kirby, E.J.M., 1985. Significant stages of ear development in winter wheat. In: W. Day and R.K. Atkin (Editors), Wheat Growth and Modelling. Plenum Press, New York, pp. 7-24.

Kirby, E.J.M., 1988. Analysis of leaf, stem and ear growth in wheat from terminal spikelet stage to anthesis. Field Crops Res., 18: 127-140.

Kirby, E.J.M. and Perry, M.W., 1987. Leaf emergence rates of wheat in a Mediterranean environment. Aust. J. Agric. Res. 38: 455-464.

Kirby, E.J.M., Appleyard, M. and Fellowes, G., 1982. Effect of sowing date on the temperature response of leaf emergence and leaf size in barley. Plant Cell Environ., 5: 477-484.

Kirby, E.J.M., Siddique, K.H.M., Perry, M.W., Kaesehagen, D. and Stern, W.R., 1989. Variation in spikelet initiation and ear development of old and modern Australian wheat varieties. Field Crops Res., 20: 113-128.

Klepper, B., Rickman, R.W. and Peterson, C.M., 1982. Quantitative characterization of vegetative development in small cereal grains. Agron. J., 74: 789-792.

Klepper, B., Rickman, R.W. and Belford, R.K., 1983. Leaf and tiller identification on wheat plants. Crop Sci., 23: 1002-1004.

Klepper, B., Belford, R.K. and Rickman, R.W., 1984. Root and shoot development in winter wheat. Agron. J., 76: 117-122.

Langer, R.H.M. and Hanif, M., 1973. A study of floret development in wheat (Triticum aestivum L.) Ann. Bot., 37: 743-751.

Large, E.C., 1954. Growth stages in cereals. Plant Pathol., 3: 128-129.

Malvoisin, P., 1984. Organogenesis and growth of the main culm of wheat from sowing to flowering. I. Relationships between leaf growth and the differentiation of young leaves of flowers. Agronomie, 4: 557-564.

Martin, J.H., Leonard, W.H. and Stamp, D.L., 1976. Principles of Field Crop Production. Macmillan, New York, 1118 pp.

Masle-Meynard, J. and Sebillotte, M., 1981. Study on the heterogeneity of a wheat stand. Study on the different sorts of individuals of the stand; factors allowing the description of its structure. Agronomie, 1: 217-224 (in French with English abstract).

McMaster, G.S., 1991. Simulating reproductive development and growth of the winter wheat shoot apex. Ph.D. dissertation, Colorado State University, Fort Collins, CO, $350 \mathrm{pp}$.

McMaster, G.S. and Smika, D.E., 1988. Estimation and evaluation of winter wheat phenology in the central Great Plains. Agric. For. Meteorol., 43: 1-18.

McMaster, G.S., Morgan, J.A. and Peterson, G.A., 1991. Wheat yield and yield components for different cropping systems, climates, and catenas. Amer. Soc. Agron. Abstracts, p. 153.

McMaster, G.S., Wilhelm, W.W. and Morgan, J.A., 1990. Simulating shoot apex development and phenology of winter wheat. In: R.C. Muchow and J.A. Bellamy (Editors), Climatic Risk in Crop Production: Models and Management for the Semi-Arid Tropics and Subtropics, An International Symposium and Workshop, 2-6 July 1990, Brisbane, Qld., INCITEC, pp. 56-57.

McMaster, G.S., Klepper, B., Rickman, R.W., Wilhelm, W.W. and Willis, W.O., 1991. Simulation of shoot vegetative development and growth of unstressed winter wheat. Ecol. Model. 53: 189-204.

McMaster, G.S., Wilhelm, W.W. and Morgan, J.A., 1992. Simulating winter wheat shoot apex phenology. J. Agric. Sci., in press. 
Miller, E.C., 1939. A physiological study of the winter wheat plant at different stages of its development. Kansas State Agric. Expt. Sta. Tech. Bull., 47.

Mishra, S.P. and Mohapatra, P.K., 1987. Soluble carbohydrates and floret fertility in wheat in relation to population density stress. Ann. Bot., 60: 269-277.

Mujahid, M.Y., 1989. Carbon isotope composition and water use efficiency of winter wheats at varying soil water content. Ph.D. Dissertation, Colorado State University, Fort Collins, CO, $114 \mathrm{pp}$.

Nuttonson, M.Y., 1948. Some preliminary observations of phenological data as a tool in the study of photoperiodic and thermal requirements of various plant material. In: A.E. Murneek and R.O. Whyte (Editors), Vernalization and Photoperiodism Symposium. Chronica Botanica. pp. 129143.

Oosterhuis, D.M., 1977. Developmental morphology of the spike of a Rhodesian spring wheat recorded with a scanning electron microscope. Rhod. J. Agric. Res., 15: 65-77.

Owen, P.C., 1971. Responses of a semi-dwarf wheat to temperatures representing a tropical dry season. II. Extreme temperatures. Expt. Agric., 7: 43-47.

Rawson, H.M. and Evans, L.T., 1970. The pattern of grain growth within the ear of wheat. Aust. J. Biol. Sci., 23: 753-764.

Rawson, H.M. and Evans, L.T., 1971. The contribution of stem reserves to grain development in a range of wheat cultivars of different height. Aust. J. Agric. Res., 22: 851-863.

Rawson, H.M., Hindmarsh, J.H., Fischer, R.A. and Stockman, Y.M., 1983. Changes in leaf photosynthesis with plant ontogeny and relationships with yield per ear in wheat cultivars and 120 progeny. Aust. J. Plant Physiol., 10: 503-514.

Ritchie, J.T., 1985. A user-oriented model of the soil water balance in wheat, pp, 293-305. In: W. Day and R.K. Atkin (Editors), Wheat Growth and Modeling. Plenum Press, New York, pp. 293-306.

Saini, H.S. and Aspinall, D., 1982. Abnormal sporogenesis in wheat (Triticum aestivum L.) induced by short periods of high temperature. Ann. Bot., 49: 835-846.

Sayed, H.I. and Ghadorah, M.O., 1984. Association of grain-filling characteristics with grain weight and senescence in wheat under warm dry conditions. Field Crops Res., 9: 323-332.

Singh, V.P. and Singh, P., 1985. Contribution of flag leaf in the development of wheat spike. Agric. Sci. Digest., 5: 49-50.

Single, W.V., 1964. The influence of nitrogen supply on the fertility of the wheat ear. Aust. J. Expt. Agric. Anim. Husb., 4: 165-168.

Sionit, N., Teare, 1.D. and Kramer, P.J., 1980. Effects of repeated application of water stress on water status and growth of wheat. Physiol. Plant, 50: 11-15.

Spiertz, J.H.J. and Vos, J., 1985. Grain growth of wheat and its limitation by carbohydrate and nitrogen supply. In: W. Day and R.K. Atkin (Editors), Wheat Growth and Modelling. Plenum Press, New York, pp. 129-142.

Vos, J., 1985. Aspects of modelling post-floral growth of wheat and calculations of the effects of temperature and radiation. In: W. Day and R.K. Atkin (Editors), Wheat Growth and Modelling. Plenum Press, New York, pp. 143-148.

Weir, A.H., Bragg, P.L., Porter, J.R. and Rayner, J.H., 1984. A winter wheat crop simulation model without water or nutrient limitations. J. Agric. Sci., Camb., 102: 371-382.

Whingwiri, E.E. and Stern, W.R., 1982. Floret survival in wheat: Significance of the time of floret initiation relative to terminal spikelet formation. J. Agric. Sci, Camb., 98: 257-268.

Wilhelm, W.W., McMaster, G.S., Klepper, B. and Rickman, R.W., 1990. Vegetative development and growth model for wheat. In: R.C. Muchow and J.A. Bellamy (Editors), Climatic Risk in Crop Production: Models and Management for the Semi-Arid Tropics and Subtropics, An International Symposium and Workshop. 2-6 July, 1990. Brisbane, Qld., INCITEC, pp. 34-35.

Williams, R.F., 1966a. The physiology of growth in the wheat plant. III. Growth of the primary shoot and inflorescence. Aust. J. Biol. Sci., 19: 949-966. 
Williams, R.F., 1966b. Development of the inflorescence in Gramineae. In: F.L. Milthorpe and J.D. Ivins (Editors), The Growth of Cereals and Grasses. Butterworths, London, pp. 74-87.

Zadoks, J.C., Chang, T.T. and Konzak, C.F., 1974. A decimal code for the growth stages of cereals. Weed Res., 14: 415-421. 